\title{
Near-decadal oscillation of water levels and mercury bioaccumulation in the Laurentian Great Lakes region
}

C.J. Watras ${ }^{1,2^{*}}$ H-Y Teng ${ }^{3}$, A.W. Latzka ${ }^{4}$, M.W. Meyer ${ }^{5}$ and Z. Zhang ${ }^{3}$

1. Bureau of Water Quality, Wisconsin Department of Natural Resources, Madison, WI, USA 53701

2. Center for Limnology, University of Wisconsin-Madison, Trout Lake Research Station, Boulder Junction WI, USA 54512

3. Department of Statistics, University of Wisconsin-Madison, Madison, WI, USA 53706

4. Bureau of Fisheries, Wisconsin Department of Natural Resources, Madison, WI, USA 53701

5. Nova Ecological Services, Manitowish Waters, WI USA 54557

*Corresponding author: Carl Watras (cjwatras@wisc.edu)
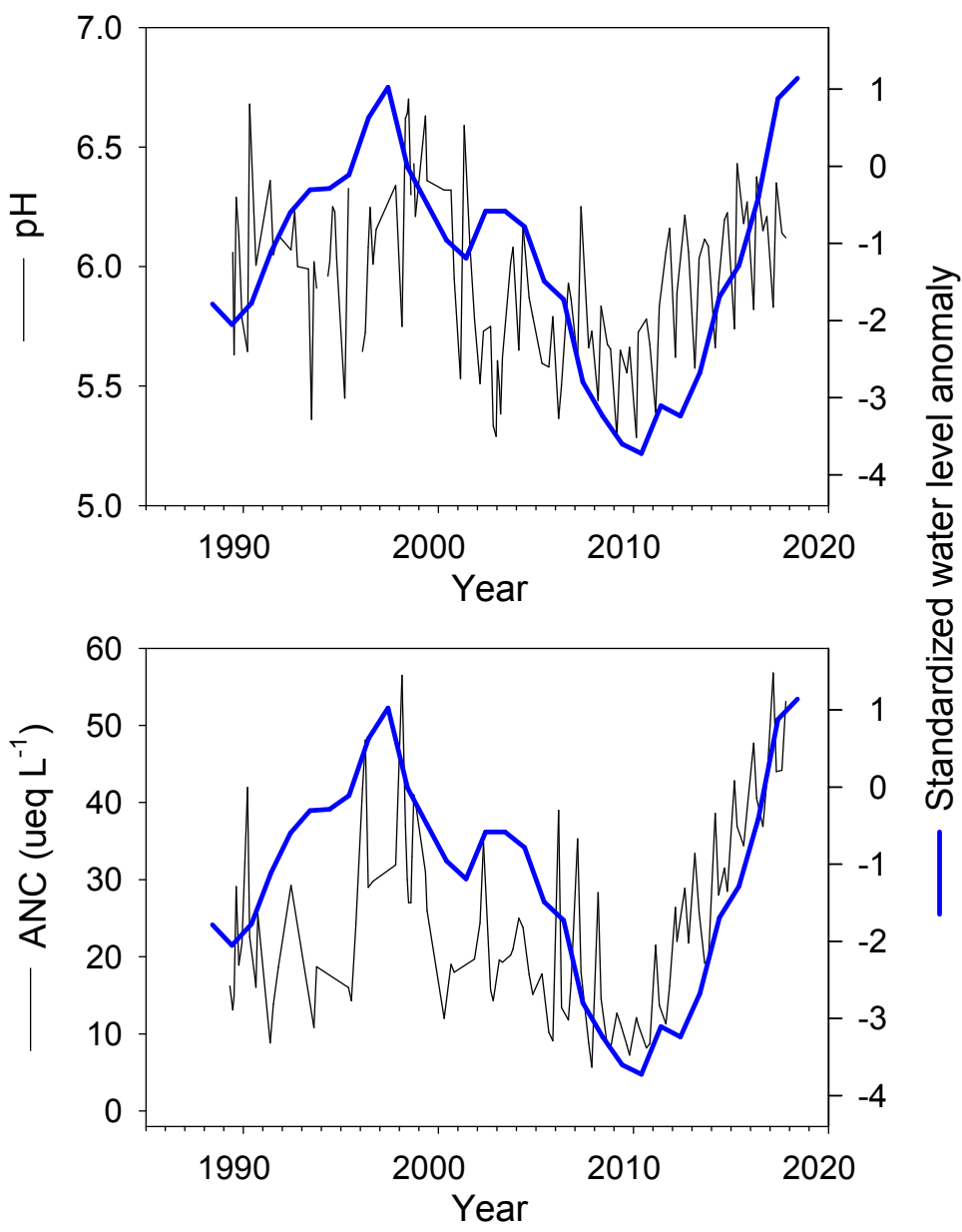

Figure S1. Oscillating acid-base status of lake water. Coherence between $\mathrm{pH}, \mathrm{ANC}$ and water level in the epilimnion of Little Rock Lake 